\title{
Identités culturelles et communication en Europe, le paradigme de la Méditerranée
}

Paul Rasse

\section{(2) OpenEdition}

1 Journals

Édition électronique

URL : http://journals.openedition.org/communicationorganisation/2345

DOI : 10.4000/communicationorganisation.2345

ISSN : $1775-3546$

Éditeur

Presses universitaires de Bordeaux

Édition imprimée

Date de publication : 1 mai 2000

ISSN : 1168-5549

Référence électronique

Paul Rasse, «Identités culturelles et communication en Europe, le paradigme de la Méditerranée », Communication et organisation [En ligne], 17 | 2000, mis en ligne le 27 mars 2012, consulté le 01 mai 2019. URL : http://journals.openedition.org/communicationorganisation/2345 ; DOI : 10.4000/ communicationorganisation.2345

Ce document a été généré automatiquement le 1 mai 2019.

(c) Presses universitaires de Bordeaux 


\title{
Identités culturelles et communication en Europe, le paradigme de la Méditerranée
}

\author{
Paul Rasse
}

1 Aborder la question des identités locales pour un chercheur est toujours risqué, qui plus est dans le champ des Sciences de l'information et de la communication, où le prestige va aux nouvelles technologies de l'information, aux mass médias, à la communication des multinationales, bref, au processus de mondialisation, dont l'Europe est un des chaînons. Le local est un sujet désuet, tout juste susceptible d'intéresser les ethnologues en mal d'exotisme, affublés d'un strabisme désobligeant qui les pousse à ne voir que les survivances du passé irrémédiablement condamné, justement par l'essor des moyens de communication. Quelques phrases bien senties suffisent généralement pour écarter brillamment l'impudent qui aurait osé aborder le problème. Les identités locales sont une survivance archaïque, au mieux un refuge illusoire pour les éclopés de la modernité, au pire une incantation mystificatrice destinée à abuser le peuple, provoquer en lui sa part d'ostracisme, jusqu'à le conduire à la haine de l'autre, aux guerres tribales et aux génocides. Et de déplorer que l'histoire ressente ne manque malheureusement pas d'exemples sanglants aux frontières d'une communauté européenne, dont on espère bien, en tous cas, qu'elle éradiquera à tout jamais cette possibilité.

2 Jusqu'à présent, la question des identités avait été l'exclusivité des anthropologues qui s'efforçaient de recenser les identités traditionnelles en train de disparaître, et éventuellement de voir comment est ce qu'elles pouvaient être réactualisées et utilisées par les mouvements revendicatifs ${ }^{1}$. D'autres se penchaient sur "melting-pot» le chaudron de l'acculturation dans lequel les sociétés les plus riches refondent les différences ethniques de leurs immigrés, ils étudiaient alors comment évoluent les identités au contact les unes des autres et de la culture dominante des pays d'accueil. Nous défendrons que les cultures locales méritent non seulement d'avantage d'attention pour leur actualité, parce qu'elles sont l'objet de nombreux processus de (re) 
construction, mais aussi, qu'il devient urgent de les penser dans leurs relations aux phénomènes de mondialisation, pour en cerner le mouvement et les enjeux avant de les traiter pour elles mêmes. Le sujet concerne les sciences de l'information et de la communication pour deux raisons paradoxales: parce que la diversité du local fonde l'échange et donc la communication, mais aussi, parce que l'essor considérable des moyens de communication conduit à la disparition des cultures ou au moins à la recomposition des identités locales, et donc avec, à bouleverser les termes de l'échange.

construction de l'Europe comme maillon intermédiaire exacerbe le débat. D'un côté, elle accélère les processus de mondialisation. De l'autre, elle pourrait bien aussi être un espace où défendre les identités régionales, par-dessus les nationalismes. Préserver la mosaïque des cultures locales, cette richesse incontestable caractéristique de la CEE, qui la différencie des autres communautés supranationales (comme l'ASEAN ou ALAMI beaucoup plus homogènes), et qui paradoxalement là aussi, pourrait bien être le moteur de son unité.

La Méditerranée, parce qu'elle est au départ le premier espace où les économies locales se sont nouées entre-elles, et parce que sur ses rivages ont ressurgi des conflits interethniques sauvages conduisant à des massacres qu'on croyait d'un autre âge, nous paraît être un bon terrain pour réfléchir à ces questions.

\section{Diversité de la Méditerranée}

Qu'est-ce que la Méditerranée demande Braudel? «Mille choses à la fois, non pas un paysage, mais d'innombrables paysages, non pas une mer, mais une succession de mers, non pas une civilisation, mais des civilisations entassées les unes sur les autres. Voyager en Méditerranée, c'est trouver le monde romain au Liban (ou en Provence), la préhistoire en Sardaigne, les villes grecques en Sicile, la présence arabe en Espagne, l'Islam turc en Yougoslavie... C'est tout à la fois, s'immerger dans l'archaïsme des mondes insulaires et s'étonner devant l'extrême jeunesse de très vieilles villes ouvertes à tous les vents de la culture et des profits qui depuis des siècles, surveillent et mangent la mer $\aleph^{2}$. L'auteur de La Méditerranée et le monde méditerranéen à l'époque de Philippe II, montre bien comment, d'une part, le milieu : montagnes, plateaux, plaines, mers et littoraux jusqu'aux confins les plus inhospitaliers a induit des systèmes agricoles, économiques, ou politiques, très différents les uns des autres, et comment d'autre part, dans le même temps, l'échange continuel entre les hommes, a permis dès l'Antiquité, l'émergence d'une unité humaine et d'un destin collectif.

6 Les côtes sont hérissées de montagnes qui «trouent la peau du pays méditerranéen » ${ }^{3}$. C'est là que s'est installée la vie. Loin des rivages marécageux et les plaines; domaine des eaux divagantes infestées de malaria, où il est difficile de se défendre. La montagne est saine, elle offre une protection quasi naturelle aux incursions des chefs de guerre, aux razzias, mais elle s'oppose à la communication; tout juste quelques mauvais sentiers "étroits, rapides, durs aux pieds des hommes et des bêtes ». Si bien que les communautés isolées les unes des autres ont dû apprendre à y vivre repliées sur elles-mêmes «vaille que vaille ", écrit Braudel, "de cultiver la vigne, le blé, l'olivier, même si le sol ou le climat s'y prêtent mal $»^{4}$.

7 Là, presque tout se perd dans l'autoconsommation. Pour se nourrir, s'habiller, habiter, il ne faut compter que sur soi et tirer le meilleur parti possible des ressources naturelles 
environnantes. Dans une lutte quotidienne, au corps à corps avec le milieu naturel, les hommes ont domestiqué les animaux, sélectionné les semences les mieux adaptées, inventé des façons de stocker leurs récoltes et de les cuisiner. Certaines fois, le bois abonde, il est amplement utilisé pour les habitations, le mobilier, l'outillage. Dans d'autres lieux, il n'y a que des pierres, à la rigueur de la terre que l'on peut cuire pour faire des briques, des tuiles et des poteries. Ailleurs encore, la vie restera nomade, parce que l'environnement ne permet aux bergers de vivre que dans une perpétuelle errance.

«La plaine, dit encore Braudel, quand elle est de bonne dimension, est restée longtemps le domaine des eaux divagantes, il a fallu la conquérir sur les marais hostiles, la protéger des fleuves dévastateurs, exorciser la malaria $»^{5}$ Sa mise en valeur exige des systèmes sociaux coercitifs, autoritaires, hiérarchisés, susceptibles de mobiliser les capitaux et les forces indispensables à la réalisation des grands travaux d'aménagement. En échange, elles supportent des classes régnantes de gros propriétaires, de bourgeois et de marchands.

Jean René Trochet ${ }^{6}$ montre bien comment les systèmes agraires, la rotation des cultures qui dépendent de la richesse des sols et des caractéristiques climatiques (biennale en Méditerranée/triennale dans les terres arrosées/alternant culture et pâtures dans les bocages), ont eu des répercussions sur les paysages, les formes d'agglomération (hameaux, villages), et les modes de vie.

10 En Méditerranée, on passe très vite d'un milieu à un autre, quelques dizaines de kilomètres parfois suffisent pour aller de la côte aux alpages, des terres fertiles et irriguées aux déserts les plus arides. Si l'on ajoute à cette rapide esquisse de la diversité des milieux, les événements politiques, les choix historiques, les solutions techniques, les accidents susceptibles de bouleverser l'ordre des choses, on imagine bien comment se sont développés des systèmes économiques, techniques et sociaux très différents les uns des autres et comment se dessinait une mosaïque des identités culturelles caractérisant chaque forme de peuplement.

\section{Unité de la Méditerranée}

11 Braudel le dit dans Dynamique du capitalisme et dans Identité de la France, «Tout village a beau faire, il ne suffira jamais à lui-même, il lui faut vendre et acheter... Si l'espace divise, il unit du fait même de cette division créatrice sans fin de besoins complémentaires; entre zones céréalières et d'élevage par exemple, entre producteurs de grain et producteurs de vin, le contact est quasi obligatoire $»^{7}$. Dans Les jeux de l'échange, réalisation matérielle, économie et capitalisme ${ }^{8}$, il étudie comment émerge ainsi, peu à peu, une circulation capillaire entre les villages et les bourgs, puis à un niveau supérieur, entre les bourgs et la ville; enfin, comment les grandes cités se donnent la main entre elles et développent les moyens d'échange, bourses, foires, comptoirs et voies de communication. Les premiers systèmes de communication, un tant soit peu performants, permettant de transporter à moindre coût et en grande quantité des marchandises et des hommes se sont édifiés sur l'eau. Les premières grandes civilisations sont nées le long du Nil, de l'Euphrate et du Tibre parce que ces fleuves ont été les premières grandes voies de navigation unifiant d'immenses territoires. Là, le vent souffle toujours de l'embouchure vers la source, si bien qu'il suffit de tendre une voile sommaire sur un mauvais radeau pour remonter le cours, puis de la baisser pour se laisser descendre, emporté par le courant. Vers l'an 2000 avant J.C, apparaissent de nouveaux navires équipés d'une quille 
et d'une voilure permettant de remonter le vent, il devient possible de traverser la mer qui n'était jusque-là qu'un immense désert. Et bientôt des marchandises de toutes sortes, mais aussi les savoirs, les goûts, les représentations du monde, s'échangent et fertilisent les civilisations, facilitant leur rayonnement. L'Égypte, la Mésopotamie, l'Asie Mineure, Mycènes, la Crète, deviennent cosmopolites, et la Méditerranée un espace économique utilitaire. Car, si la Méditerranée «fait le pêcheur pauvre, elle fait la fortune du commerçant... Depuis les marins phéniciens, qui, poussés par les besoins du négoce, ont reconnu ses côtes les plus lointaines, c'est sur la mer que ce sont édifiées les plus belles fortunes et avec elles les civilisations les plus brillantes »". Et Braudel d'ajouter «la décadence, les crises, les malaises de la Méditerranée, ce sont justement les pannes, les insuffisances, les cassures du système circulatoire qui la traversent, la dépassent et l'entourent, et qui des siècles durant l'avaient mise au-dessus d'elle-même " ${ }^{10}$.

Quand pour une raison ou une autre ${ }^{11}$, les communications s'interrompent, les cultures se replient sur elles-mêmes, comme un escargot se rétracte dans sa coquille. Au IIè siècle avant JC, la Méditerranée orientale retombe au point zéro, pendant cinq siècles, jusqu’à ce que la navigation hauturière retrouve ses forces, alors les Grecs partent à la conquête de l'ouest et bientôt les colonies, Carthage et les villes de Sicile sont plus brillantes que leurs métropoles d'origine. Le même phénomène se reproduit chaque fois, rythmant le début et la fin des grandes civilisations. Mais les crises, les décadences, les ruptures, même quand elles durent des siècles, n'arrêtent pas le cours de l'histoire: l'essor inexorable des moyens de communication qui nouent les économies et les sociétés entre elles.

Quand, à partir de la seconde moitié du XIXe ${ }^{e}$ les réseaux de communication ferroviaires puis routiers se développent, depuis longtemps déjà la Méditerranée n'est plus le centre. L'ouverture de nouvelles voies maritimes ont étendu les moyens d'échange à la planète tout entière, déplaçant le centre de gravité vers l'Europe du Nord et ses grands ports ouverts sur le nouveau monde. Ils entraînent une recomposition de l'économie et rendent possible la spécialisation des espaces dans telle ou telle production artisanale, agricole ou industrielle. Certaines cultures vivrières, par exemple, vont décliner parce que le rendement est mauvais et qu'on peut les importer à bon compte d'autres contrées où elles se trouvent en abondance. D'autres productions, au contraire, se développent parce qu'elles tirent un meilleur parti du terroir, que les hommes s'en sont fait une réputation et que leur exportation contribuera à équilibrer la balance des échanges commerciaux. Les économies locales se repositionnent autour de pôles d'excellence et se spécialisent ; ce qui contribue à l'émergence de nouvelles identités ${ }^{12}$.

14 La Toscane est devenue ainsi le plus beau paysage de la Méditerranée, remarque Braudel, parce qu'elle a pu se spécialiser dans la culture de l'olivier et de la vigne, étant approvisionnée en grains depuis la Sicile par les grands ports qui se développent à proximité1 ${ }^{13}$. Victor Scardigli, qui travaille sur la dynamique des identités locales en Europe, montre comment au XIX ${ }^{e}$, se constituent des pôles de spécialisation industrielle. À Bologne, des statistiques de 1897 mentionnent l'existence d'une industrie textile domestique, utilisant 7370 métiers à tisser destinés à filer le chanvre cultivé aux alentours. À Carpi près de Modène, une industrie locale de fabrication de chapeaux de paille vendus dans le monde entier, emploie en 1904 trente à quarante mille personnes ${ }^{14}$. La Catalogne, quant à elle, après s'être spécialisée dans la viticulture, se tourne vers le textile, d'abord le lainage, ensuite le coton; et là encore, assez rapidement, le marché dépasse les frontières régionales, s'étend sur le continent, gagne l'Amérique du Sud ${ }^{15}$. 
la fin du XVIII , la corporation des gantiers-parfumeurs qui excelle dans la fabrication des parfums extraits de plantes odorantes récoltées dans les garrigues provençales découvre un nouveau procédé technique permettant de capter la fragrance des fleurs les plus fragiles. Le succès des nouvelles fabrications est tel que les plus audacieux ou les plus riches d'entre eux construisent de grandes usines, tandis que les campagnes environnantes se couvrent de plantes à parfum, Un siècle plus tard, pour répondre à la demande croissante, les grassois font cultiver le jasmin, la rose, la fleur d'oranger, la cassie, dans tout le bassin méditerranéen, partout où les conditions géoclimatiques sont favorables, la main-d'œuvre abondante et peu onéreuse, en Italie, en Grèce, en Bulgarie, en Égypte, en Algérie, en Israël... dans leur affinement et la composition des grands parfums commercialisés dans toutes les grandes métropoles de la planète. Elle devient véritablement la capitale mondiale de la parfumerie, pour la qualité de ses produits, autant que pour sa capacité à contrôler l'ensemble des réseaux d'approvisionnement et de commercialisation.

Ailleurs, ce sont des denrées agricoles comme le fromage, la charcuterie, le vin, ou des fabrications artisanales telles que la poterie, la teinture, la métallurgie, qui pour une raison ou une autre connaissent un essor sans précédent et conduisent une fraction de plus en plus large de la communauté à s'y consacrer, devenant un pôle d'excellences de la contrée. On améliore les techniques, on spécialise les machines, on développe les réseaux d'approvisionnement et de commercialisation, ce qui contribue encore à l'hégémonie de ces nouvelles fabrications.

Bientôt, dans chaque bassin d'emploi, la communauté tout entière se réorganise autour des nouveaux pôles d'activités, qu'ils soient agricoles ou industriels. Elle développe des savoir-faire, des pratiques, des attitudes professionnelles, des formes d'organisation sociale, de nouvelles habitudes alimentaires ou vestimentaires qui lui sont spécifiques et la caractérisent. Déjà les techniques, en se diffusant d'un centre industriel à l'autre, tendent à uniformiser les façons de travailler autour du métier, tandis que le déracinement des populations et leur prolétarisation dans les grands centres industriels contribuent, eux, à l'uniformisation de la classe ouvrière ${ }^{17}$.

19 Ensuite, quand le mouvement s'accélère, les réseaux routiers, maritimes, fluviaux, ferroviaires, aériens permettent d'acheminer toujours plus de matières à des coûts toujours plus bas. Et un jour, il devient plus intéressant de transporter d'un bout à l'autre de la planète les productions les plus insignifiantes ou les denrées les plus périssables que de continuer à les fabriquer sur place. Dès lors que l'essentiel des produits que l'homme consomme pour son existence provient d'un peu n'importe où, les rapports qu'il entretient avec son terroir ne reposent plus sur aucune nécessité et ne valent souvent plus que pour le souvenir. Les particularités culturelles qui en découlaient se maintiennent autant que se perpétuent les traditions, mais vont en s'atténuant et finissent par s'éteindre, à moins qu'un effort désespéré ne soit fait pour en maintenir le souvenir.

«L'histoire de la civilisation, résume Daniel Bougnoux, se confond ainsi avec celle d'un détachement progressif $d u$ territoire millénaire, mais aussi ajoute $t-i l$, avec une dématérialisation lente des supports et des produits du travail humain, avec la promotion et la circulation accélérée des signes... ${ }^{18}$. Car les systèmes de communication ne servent 
pas seulement à acheminer de la matière, mais aussi, au brassage des populations, à l'échange des idées, à la diffusion des modes de vie, des principes de travail ou des façons de consommer. Progressivement, les cultures se fondent dans un cercle de plus en plus large, jusqu'au cercle le plus large d'une culture mondiale qui tend à dominer et à se faire exclusive tandis que le premier cercle, celui de la communauté d'origine a disparu. Un jour, la prédiction de Mc Luhan se révèle en cours de réalisation. "À l'aube de l'âge électronique, l'englobement de la grande famille humaine tout entière en une seule tribu globale $»^{19}$.

\section{Dynamique patrimoniale et développement local}

21 Dans les années soixante, la stratégie des élus locaux les plus dynamiques était d'inscrire leur région dans la modernité et de l'intégrer à l'ensemble national et européen. Pour cela, ils ont misé sur le développement des infrastructures de communication et des grands réseaux internationaux (routes, autoroutes, T.G.V., et lignes d'aviation). Faisant "table rase du passé", ils ont grand ouvert leurs portes aux aménageurs. Et puis progressivement la situation a évolué. Si le tourisme est incontestablement la première industrie des régions d'Europe situées au bord de la Méditerranée, l'exploitation forcenée des sites touristiques privilégiés conduit à leur défiguration et par là même à mettre en péril la dynamique de développement de ces régions, dont témoigne la baisse de fréquentation touristique de certains espaces dévastés. À l'instigation de la Charte européenne du patrimoine adoptée en 1975 par le Conseil de l'Europe, les aménageurs du territoire prennent peu à peu conscience de la nécessité de conserver non seulement les monuments majeurs, les sites classés, mais aussi le petit patrimoine, fragile, les centre villes, le bâti rural même le plus modeste, et les sites qui représentent un intérêt historique, archéologique, artistique, scientifique, social ou technique. Ensemble, «ils sont une part essentielle de la mémoire des hommes qui ont ainsi conscience de leur propre durée. S'ils ont généralement contribué dans le passé à éviter la ségrégation sociale, ils peuvent aujourd'hui permettre aux populations de conserver ou de trouver leur identité et de se prémunir contre les mutations brutales de la société $»^{20}$.

Par opposition au concept d'aménagement du territoire, planifié par le haut, par l'État technocratique dans la perspective de réalisations gigantesques, le développement local vient de la base, il travaille sur de petits projets à la rentabilité aléatoire, souvent dans des zones en perte de vitesse, n'intéressant pas les investisseurs institutionnels. Il s'efforce d'associer les populations dans leurs différentes composantes (élus locaux, acteurs économiques et culturels, associations...), de recenser les potentialités, techniques, humaines, économiques, culturelles d'un territoire, de fédérer les ressources et les initiatives pour les mettre en synergie et les dynamiser. Il fait émerger une représentation forte et originale du territoire dans une perspective culturelle (identitaire), économique (développer des activités nouvelles), sociale (créer de l'emploi, permettre aux populations de vivre sur place), d'amélioration de la qualité de la vie, (aménagement du cadre de vie, protection de l'environnement, sociabilité, entraide et loisirs...).

Les deux conceptions s'opposent, mais ne sont pas antinomiques, au contraire elles se complètent; niveau global et niveau local sont la condition l'une de l'autre. Contre la tendance à l'uniformisation des paysages, des lieux urbains, des modes de vie, des façons d'êtres et de faire, l'appel à l'identité est un ressaisissement de la collectivité menacée de 
se dissoudre dans une sous-culture mass médiatique, non pas pour refuser la mondialisation, mais pour y participer comme acteur s'efforçant de sauvegarder son intégrité et de maitriser sa destinée. La collectivité exhume, retrouve, produit, crée tout ce qui peut la caractériser, non point pour l'isoler, mais pour en faire une ressource commune du groupe, une force de cohésion, un ensemble de repères pour orienter l'action et développer des processus d'adaptation au changement.

«La mémoire régionale reste la source de l'identité »" ${ }^{21}$. Aujourd'hui il s'agit «de mettre en scène le patrimoine, hier voué aux bulldozers... Dans le même temps, tous les éléments matériels et immatériels censés incarner les cultures locales sont convoqués à l'appui de la nouvelle politique $»^{22}$. Il faut non seulement les restaurer, mais encore les instaurer comme témoins symboliques censés représenter l'identité du site. Là encore, les élus ne s'y sont pas trompés, l'enjeu est de taille, alors que les aménagements de la période précédente dévalorisaient le territoire aussi vite qu'eux-mêmes se dévalorisaient, «le retour à des valeurs identitaires » devient dans l'Europe des régions une richesse, « une valeur d'échange ${ }^{23}$. Peu à peu, la protection de l'environnement, des paysages, la mise en valeur d'ensembles patrimoniaux, le maintien ou l'instauration de manifestations culturelles originales, la revalorisation des produits du terroir, des spécialités culinaires ou de fabrications artisanales et industrielles locales réputées, le tourisme vert, culturel, d'affaires... deviennent un des axes forts des politiques d'aménagement et de développement économique des régions ${ }^{24}$. Consensuel, le processus mobilise l'ensemble des forces vives d'un territoire: élus, chefs d'entreprise, animateurs d'associations, artistes, érudits, chercheurs, experts en communication, pour dégager, préserver, faire vivre ce qui caractérise leur ville, leur profession, leur région et la rend unique. " La diversité n'est pas la résultante des forces abstraites, elle est l'œuvre des acteurs sociaux... poursuivant dans leur action quotidienne un véritable projet de société, qui prolonge cette histoire spécifique. Ainsi, l'identité d'une région c'est à la fois le passé vécu par ses acteurs et un avenir voulu par eux $»^{25}$.

La multiplication récente des petits musées de société, d'art et tradition populaire conçus pour conserver et mettre en scène des collections d'objets investis comme le témoin de la mémoire locale est révélateur de ces nouvelles préoccupations identitaires. À l'origine on trouve toujours un groupe de passionnés issus de la population locale, ou pour le moins, enracinés dans le tissu économique, politique et social du territoire. Il doit commencer par faire ses preuves devant l'habitant, pour le rallier à sa cause. La première étape consiste d'ailleurs, autant à convaincre la population de la valeur symbolique des vestiges que de la nécessité de les conserver dans un musée. Un dialogue s'engage avec les habitants. Il porte sur l'intérêt de conserver et de maintenir en l'état les pauvres témoignages d'une vie de misère, que la plupart ont fui pour aller vivre en ville, et que ceux qui restent voudraient brader au profit de représentations nouvelles, susceptibles d'affirmer l'inscription de leurs pays dans la marche du progrès. Muséifier l'espace, n'estce pas ajouter à sa désertification en le vitrifiant ? Protéger l'environnement, n'est-ce pas faire obstacle à la libre entreprise et au droit de la propriété ? Défendre l'identité d'une communauté, n'est-ce pas encourager ses penchants archaïques au repli et à l'ostracisme? Quel intérêt de s'ingénier à conserver des métiers et des savoir-faire de toute façon condamnés? Pour convaincre de la justesse de ses positions, l'association s'appuie sur les nouveaux arrivés et sur les immigrés ayant gardé une résidence au pays. Elle porte le débat partout où elle le peut. Elle multiplie les points de contact avec la population locale pour assurer la publicité de son projet: jusqu'à convaincre la 
municipalité de s'engager à ses côtés. Souvent le mouvement de production identitaire réactive des conflits latents, oppose différents groupes sociaux "les pour, les contre", «les anciens, les nouveaux", «les concernés, les indifférents", «les militants, les notables, les autres » Mais n'est-ce pas là, de toute façon, enclencher une dynamique de débat sociale fertile qui génère de l'appartenance, autant que de la différence ${ }^{26}$.

Une des façons privilégiées pour communiquer avec la population, la rassembler et donner en représentation aux élus son assentiment, consiste à organiser de grandes manifestations, fêtes populaires, vernissages d'expositions temporaires, manifestations touristiques... comme moment fort de la vie de l'institution où sont conviés les amis, les élus... Et la presse locale s'en fait l'écho en assurant la publicité auprès de l'ensemble de la communauté. « À l'extrême, écrit Jean Davallon à propos des écomusées, on pourrait dire qu'ils visent moins à muséifier le territoire qu'à le transformer en lieu de cérémonie... ${ }^{27}$. Le rassemblement est non seulement un moment de présence que la communauté s'accorde à elle-même, mais elle incarne l'intérêt qu'elle accorde à son patrimoine où elle se donne à voir dans sa différence, pour elle même et pour l'étranger. Et ce regard croisé contribue au sentiment de son identité... ${ }^{28}$

Alain Morel met en évidence un certain nombre de dérives vers une reconstruction artificielle, néo-artisanale, néo-rurale, néo-médiévale, purement factice et sans aucun rapport avec la réalité historique du lieu. Mais en dehors de cas extrêmes, qui paraîtront de moins en moins crédibles et feront d'autant moins recette, que la culture, l'expérience, les exigences des visiteurs évoluent, il faut admettre que tout processus identitaire porte en lui une part de construction, d'invention, de controverse. N'est-ce pas d'ailleurs ce qui en fait la richesse et garanti qu'il n'est pas une quête d'essence originelle pure et figée ?

Bien sûr tout cela est encore bien confus, à l'état d'esquisse, souvent relégué au second plan par des réalisations prestigieuses captant tout l'argent des collectivités et l'intérêt des médias. Mais le mouvement est profond, il donne lieu à une multitude d'initiatives modestes qui ne finissent par s'imposer qu'à force de d'acharnement, en mobilisant de larges fractions de la population (ainsi que nous l'avons vu pour les musées) jusqu'à s'imposer aux élus comme une évidence incontournable et obtenir leur soutien.

\section{Identité de la Méditerranée}

Dans cette nouvelle dynamique, la Méditerranée occupe une place de choix, inégalée, inégalable. Partout affleurent les vestiges des civilisations anciennes qui y ont rayonné; partout, on peut lire le travail modeste et acharné, sempiternel des communautés ayant façonné ces paysages. La Méditerranée, n'est-ce pas d'abord l'histoire des hommes qui ont habité cette terre, s'efforçant tantôt de se prémunir contre la sécheresse de l'été, les pluies torrentielles, le lancinement des vents, tantôt d'exploiter les potentialités climatiques et physiques de chaque territoire pour en tirer le meilleur, inventant des façons de cultiver, d'élever, de fabriquer, de construire, de boire et de manger, de festoyer ou d'enterrer ses morts, de célébrer les dieux et d'exprimer la puissance des princes $^{29}$.

30 En même temps, la Méditerranée c'est le bleu au fond de tous les paysages; la mer fait l'unité, parce qu'elle adoucit la véhémence du climat, mais surtout qu'elle facilite la circulation des marchandises, des hommes et des idées. Elle permet l'essor de civilisations prestigieuses et leur déploiement de rivages en rivages. Elle assure une permanence, 
même dans les poches où persistent des tribus archaïques, même aux époques de repli et de fragmentation des civilisations en microsociétés féodales.

La Méditerranée est une terre d'accueil et de rencontre, pour l'émerveillement des artistes, la sensibilité des écrivains, la fertilité des scientifiques, l'ambition des politiques, l'ingéniosité des artisans, l'audace des commerçants et des industriels. Elle est cet effet d'ombre et de lumière, cette fascination des couleurs trop vives et si douces à vivre, cet alanguissement de temps qu'alternent des zones d'hyperactivité, ce mélange d'authenticité et de superficialité exubérante, la réputation de fabrications artisanales séculaires et la maitrise des technologies les plus sophistiquées, cet ancrage dans le passé, mais cette capacité à se projeter dans l'avenir. Tout cela constitue un patrimoine unique à conserver et à partager, si l'avenir est devant, ce dont nous sommes bien certains, c'est en assumant l'héritage des générations passées, en le restaurant comme une richesse revisitée par le présent, que les populations méditerranéennes assumeront leur devenir.

Jusque là, la douceur du climat, la beauté des paysages, paraissaient suffisant aux bonheurs des autochtones, tandis que les congés payés et l'engouement pour les bains de mer semblaient être une ressource inépuisable de développement touristique et économique. Mais les systèmes de transport se sont encore développés mettant à en concurrences les plages et les îles paradisiaques du monde entier. À l'aune des trois « $\mathrm{S}$ » : sun, sand, sea, la Méditerranée surpeuplée et abîmées fait moins recette. Il reste à développer ici et là, à cultiver partout en Méditerranée, une identité originale, authentique, qui ne soit pas seulement la déclinaison moyenne, standardisée, fallacieuse, d'un exotisme de pacotille emprunté aux îles du Pacifique ou aux modes de vie californiens, mais au contraire, sache s'appuyer sur l'histoire et le patrimoine qui font la diversité de chacune des régions et l'unité de la Méditerranée. « Est-ce trop attendre de la communication moderne, demande Daniel Bougnoux, qu'elle ne favorise ni le renferment tribal, ni l'universalisme abstrait, mais la pluri-appartenance et les identifications tournantes $»^{30}$. Et plus les phénomènes de mondialisation iront en s'accélérant, plus il conviendra de défendre les identités locales, pour en faire une ressource des autochtones, un critère de leur qualité de vie, mais aussi une force de leur ouverture au monde.

33 La médiation du patrimoine est une forme moderne de l'hospitalité, une façon d'accueillir l'étranger, quand, dans le respect des différences, les hôtes donnent à voir et à comprendre le meilleur d'eux-mêmes, ce dont ils sont le plus fier, qui fait leur originalité, leur excellence et les rend remarquables. Les musées, les maisons de pays, les offices de tourisme, ne sont-ils pas, implicitement au moins, conçus dans cette perspective? N'estce pas leur mission essentielle d'accueillir le visiteur étranger ; non point pour se jouer de son ignorance et exploiter son pouvoir d'achat, mais pour lui permettre de découvrir un site dans ce qu'il a d'exceptionnel.

34 La défense des identités locales fortes et leur médiation dans des espaces conçus pour l'accueil et l'information de l'étranger, sont la justification l'une de l'autre, jusqu'à devenir un des moteur de l'économie locale et fournir en énergie les réseaux de communication. "Il s'agirait, recommande Morin, d'aller vers une société universelle fondée sur le génie de la diversité et non sur le manque de génie de l'homogénéité, ce qui nous conduit à un double impératif, qui porte en lui sa contradiction mais qui ne peut se féconder que dans la contradiction: 1) partout préserver, étendre, cultiver, développer l'unité ; 2) partout préserver, étendre, cultiver, développer la diversité $»^{31}$. 


\section{NOTES}

1. Tap Pierre (sous la direction de), Identité collective et changements sociaux, Ed. Privat, 1980.

2. Braudel Fernand (sous la direction de), La Méditerranée, Paris, Arts et métiers Graphiques, 1986, p. 7 voir aussi : Braudel Fernand, La Méditerranée et le monde méditerranéen à l'époque de Philippe II, tomes I et II, Paris, Ed. Armand Colin, 1987 (première édition 1949). Braudel Fernand, L'identité de la France, Espace et Histoire, tomes I II et III, Paris, Ed. Champs Flammarion, 1990. Braudel Fernand, La dynamique du capitalisme, Paris, Ed. Champs Flammarion, 1988. Braudel Fernand, Civilisation matérielle, économie et capitalisme au $\mathrm{XV}^{\mathrm{e}}$ et $\mathrm{XVIII}^{\mathrm{e}}$ siècle, tome I, II et III, Paris, Ed. Armand et Colin, 1987/1988 (première édition 1979).

3. Braudel Fernand (sous la direction de), La Méditerranée, op. cit. p. 16

4. Voir aussi La Méditerranée et le monde méditerranéen à l'époque de Philippe II, p. 29 et suivantes

5. Braudel Fernand (sous la direction de), La Méditerranée, op. cit., p. 2) et Braudel Fernand, La Méditerranée et le monde méditerranéen à l'époque de Philippe II,, op. cit., p. 59

6. Trochet Jean René, Différence dans les campagnes françaises de jadis, systèmes agraires et traits culturels, in La différence, catalogue de l'exposition, Grenoble, Ed. du Musée Dauphinois, 1995.

7. Braudel Fernand, Identité de la France, t. 1, op.cit., p. 12,

8. Braudel Fernand, Les jeux de l'échange, réalisation matérielle, économie et capitalisme, Paris, Ed. Armand Colin, 1988, pp. 96 et suivantes.

9. Braudel Fernand (sous la direction de), La Méditerranée, op. cit., p. 46

10. Idem, p. 64

11. Les bateaux par exemple ont conduit à la déforestation. La cherté du bois qui s'en suit aura été l'une des raisons de la décadence de la Méditerranée au XVI ${ }^{e}$ siècle. La Méditerranée, op. cit., p. 61.

12. Rasse Paul, Techniques et cultures au musée: Ingénierie et communication des musées de société, Lyon, Ed. PUL (Presses Universitaires de Lyon), 1997.

13. Braudel Fernand (sous la direction de), La Méditerranée, op.cit. p. 62.

14. Cappecchi Vittorio, Pesce Adèle, L'Emilie Romagne, in L'Europe de la diversité (Sous la direction Victor Scardigli), Paris, Ed. CNRS, 1993, p. 97.

15. Roque Maria Angels, Gallardo Virgini, La Catalogne, in L Europe de la diversité (Sous la direction Victor Scardigli), Paris, Ed. CNRS, 1993, p. 45.

16. Cf. Rasse Paul, La cité aromatique, Ed. Serre, 1987 - La cité Aromatique : Culture, techniques et savoir-faire, Terrain $\mathrm{N}^{\circ} 16, \mathrm{MSH} /$ Ministère de la culture, 1991.

17. Rasse Paul, Identité, techniques et musées en Europe, in Alliage spécial Europe, $\mathrm{N}^{\circ} 15 / 16$, Nice, Ed. Anais / Z'éditions, 1993, diffusion Seuil.

18. Bougnoux Daniel, Expression identitaire et communication moderne, in Saez Jean-Pierre (sous la direction de), Identité, culture et territoire; Ed. Desclée de Brouwer, 1995, p. 103.

19. Vers la fin des années 60 , Me Luhan annonçait déjà une "société tribale planétaire ", cité in Le Dictionnaire de la Sociologie, Paris, Marabout Université, 1972.

20. Doerr H. Breton C, Le métier de médiateur au patrimoine intégré, Étude et réflexion $N^{\circ} 19,1996$.

21. Scardigli Victor, l'Europe de la diversité : la dynamique des identités régionales, op.cit., p. 228.

22. Bartement Daniel, Bernier-Boissard Catherine, La région, entre pratique institutionnelle et production idéologique, in Sciences de la société, n³4, 1995, p. 145.

23. Bartement Daniel Bemier-Boissard Catherine op.cit. p. 144. 
24. Voir par exemple : Faure Muriele, Un produit agricole affiné en objet culturel, in Terrain $n$ -33, éd. Du patrimoine/Ministère de la Culture, 1999, pp. 81-92, Escallier Christine, Mode de consommation et manières de table dans les alpes du Sud, in Dynamique des pratiques alimentaires, Technique et cultures $\mathrm{N}^{\circ} 31$ et 32, 1998, pp. 175192

Castellana Robert, Nouritures de l'identité dans les Alpes de méditerranée, in Technique et cultures $\mathrm{N}^{\circ} 31$ et 32, op.cit. pp. 193202

Fournier Dominique, Jamard jean Luc; Pratiques alimentaires pratiques identitaires. Changement en basse Andaluosie, in Technique et cultures $\mathrm{N}^{\circ} 31$ et 32, op.cit. pp. 219240

25. Scardigli Victor, l'Europe de la diversité, op. cit., p. 232.

26. Morel Alain, Politiques culturelles, productions d'images et de développement local, in Saez Jean-Pierre (sous la direction de), Identité, culture et territoire, Ed. Desclée de Brouwer, 1995, p. 131 et suivantes.

27. Davallon Jean, Claquemurer pour ainsi dire, tout l'Univers, Ed. Centre de création industrielle, Georges Pompidou, 1986 p. 120.

28. Rasse Paul, Les musées à la lumière de l'espace public : histoire, évolution, enjeux. Ed. L'Harmattan, 1999

Rasse Paul, Techniques et cultures au musée, Éd. PUL, 1997

29. Voir aussi les travaux de Marie Joseph Bertini qui utilise le paradigme de la Méditerranée pour comprendre les phénomènes de métissage, de mondialisation et d'universalisation à l'œuvre dans les sociétés contemporaines, notamment grâce aux réseaux électroniques et à internet: Bertini Marie Joseph, Pour une culture réticulaire: la pertinence du paradigme méditerranéen, Recherches en Communication, $\mathrm{n}^{\circ}$ 9, 1998.

Bertini Marie Joseph, Les opérations culturelles en réseaux: la pertinence du modèle méditerranéen, in Communication, Société et Internet, Ed. L'Harmattan, 1998.

30. Bougnoux Daniel, Expression identitaire et communication moderne, in Saez Jean-Pierre (sous la direction de), Identité, culture et territoire, Ed. Desclée de Brouwer, 1995, p. 109.

31. Morin Edgar, Kern Anne Brigitte, Terre patrie, Paris, Ed. du Seuil 1996, p. 143.

\section{RÉSUMÉS}

Identités culturelles et communication en Europe : le paradigme de la Méditerranée. Les cultures locales méritent notre attention parce qu'elles sont l'objet de nombreux processus de (re) construction. Il devient urgent de les penser dans leurs relations aux phénomènes de mondialisation, pour en cerner le mouvement et les enjeux. Nous défendrons que la diversité du local fonde l'échange et donc la communication, paradoxalement l'essor considérable des moyens de communication conduit à la recomposition des identités locales, et donc avec, à bouleverser les termes de l'échange. La Méditerranée, parce qu'elle est au départ le premier espace où les économies locales se sont nouées entres elles, et parce qu'aujourd'hui la redéfinition de son identité fait problème, constitue un paradigme utile pour aborder ces questions.

Cultural Identifies and Communication in Europe, The Mediterranean Paradigm. Local cultures deserve our attention since they are subjects to a constant (re) - construction process. Thinking of them in terms of relations to globalisation now becomes urgent in order to grasp their 
evolution and stakes. We defend the idea that local diversity is at the origin of exchange and therefore communication.

Paradoxically, a considerable growth in the means of communication leads to the reconstruction of local identities, as well as the upheaval in exchange conditions. As it was the original place where local economy came in contact, and with the problem of its new identity definition, The Mediterranean Sea constitutes a necessary paradigm to face these issues.

INDEX

Mots-clés : communication, Europe, identité, médiation, mémoire, patrimoine

\section{AUTEUR}

\section{PAUL RASSE}

Paul Rasse, Maître de conférences, habilité à diriger des recherches. Codirecteur du LAMIC (Laboratoire de recherche sur la mémoire, l'identité et la communication). Directeur du DESS : Médiation et ingénierie culturelle (mention Communication Scientifique et Muséologie). Enseignant du Département Art, Communication, Langages, Université de Nice Sophia Antipolis. Université de Nice Sophia Antipolis - Faculté des Lettres, Arts et Sciences Humaines. E-Mail : rasse@unice.fr 